\title{
Introduction to Signs and Communication in Mimicry
}

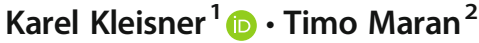

Received: 5 March 2019 / Accepted: 18 March 2019 / Published online: 30 March 2019

(C) Springer Nature B.V. 2019

Why dedicate a special issue of Biosemiotics to mimicry? Is there anything new one could say about mimicry that was not said elsewhere? Given the size of mimicry studies, one could argue that almost everything worth saying has been already said. But in some cases, it was a long time ago, in other cases, it was overshadowed by the mainstream opinions of the day, and yet other insights just slipped through the cracks because their authors were outsiders to the world of 'big science.' Biosemiotics, a discipline that studies sign systems and meaning production in the living world, approaches the phenomenon of mimicry in part by analysing iconic signs (where a sign refers to its object because of mutual resemblance) and by emphasising the intentionality of semiosis and interspecies semiotic relations. Biosemiotics thus provides a fresh approach to the study and analysis of mimicry by highlighting the communicative and meaning-laden aspects of such deceptive similarities. The goal of this special issue is thus to advance a semiotic and communicative approach to the interpretation of mimicry, an approach which we believe has relevance to both a biological theory of mimicry and to general biosemiotic theory.

The study of biological mimicry has a long and distinguished history in biology, starting with its use as an argument in support of Darwinian theory of evolution. Alfred Russel Wallace and Henry Walter Bates realised that some butterfly coloration might be adaptive because of its resemblance to other lepidopteran species. Bates suggested that this resemblance can best be explained by natural selection (Bates 1862: 512). Mimicry thus came to be viewed in modern times as a convincing instantiation of the creative powers of natural selection.

Such mimicry has traditionally been viewed as a system of three parts, where the mimic or imitator organism takes on appearance of the model organism, which is usually protective, and the mimic's taxonomic identity is therefore misinterpreted by

Karel Kleisner

karel.kleisner@natur.cuni.cz

Timo Maran

timo.maran@ut.ee

1 Department of Philosophy and History of Science, Charles University, Prague, Czech Republic

2 Department of Semiotics, University of Tartu, Tartu, Estonia 
the perceiver (usually a predator). In short, the mimic acquires an evolutionary advantage by adopting the appearance of a protected model. This classical setup is known as Batesian mimicry. From the perspective of the current Special Issue, it is, however, interesting to note that this classical tripartite mimicry system, consisting of a mimic, a model, and a perceiver, can also be viewed as a communicative setup. Mimicry as a communication system includes 'a communicative relationship between the model and the receiver as a resemblance-based relation between the model and the mimic, and as a deceptive relation between the mimic and the receiver' (Maran 2010: 351).

In some cases, however, both the mimic and the model are protected (e.g., by poison, sting, or unpalatable contents). This situation was first described by Fritz Müller, who supported his idea by a simple mathematical model (Müller 1878), and thus this type of mimicry is called Müllerian. In some cases, however, lethally poisonous mimics imitate less poisonous or unpalatable models: this setup is known as Mertensian mimicry (Wickler 1968; Emsley 1966; Mertens 1956). In yet other situations, a predator gains advantage by imitating someone's prey. This is called aggressive or Peckhamian mimicry (Peckham and Peckham 1892). Rather frequent are cases where relations characteristic of Batesian and Müllerian mimicry combine to form complex mimicry rings with varying degree of mutualism and parasitism on the model's protective potential. Instances of mimicry of highly varied and proposed types and typologies are numerous. It is not, however, the goal of this issue to provide a comprehensive overview of the history or theory of mimicry studies (however, see Wickler 1968; Komárek 2003; Quicke 2017; Maran 2017).

The phenomenon of mimicry is so diverse that one could doubt whether all of its instances can or should be covered by a single umbrella term. Indeed, one could ask what do molecular mimicry, where a virus imitates the proteins of a host organism, vocal mimicry of birds, and sexual mimicry used for intraspecies communication have in common? We are aware of the fact that mimicry classification systems introduce various criteria in order to distinguish other kinds of interspecies similarities and deceptions which were historically subsumed under the term mimicry (and use terms such as convergence, masquerade, homotypy, etc.). Nevertheless, we decided to embrace the concept of mimicry in its full richness, that is, we prefer thinking of mimicry in sensu lato instead of adopting any of the stricter definitions that have been proposed.

We thereby take the risk of opening up a space for discussing mimicry not only within its biological, behavioural, and informational connotations, but also in its anecdotal, social, historical, cultural, and artistic contexts. Why do we insist on such a fuzzy concept of mimicry? Despite the vast and often logical differences between the various phenomena historically subsumed under the term mimicry, all this multitude shares a common denominator. 'Meaning' is the condition sine qua non for the existence of mimicry. One could imagine, for instance, a mathematical relation between two structures in a biological hyperspace, but that would not be mimicry because such a relation would not be cognitively mediated. In other words, meaning would be absent. Mimicry is always constructed by living participants: imitators, models, perceivers, and sometimes it is even co-constructed by us humans. A double construction thus appears to be a paradoxical characteristic of mimicry: first, the relationship needs to be confusingly perceived by an animal perceiver and secondly, the situation needs to be identified as mimicry by a researcher. 
Moreover, imitation is also of key importance in human ontogenesis and culture. By imitating others, we search for our place in society and, despite the initial inspiration from the various models with whom we interacted in the course of our development, in the end we become separate, distinct individuals. This 'human' dimension of mimicry includes the unconscious copying of facial expressions, counterfeit money or other valuables, and also, for instance, mimesis (in the form of resemblance-based artistic representation).

Explanations of mimicry are as thus variable as the phenomenon itself. The various cases of mimicry involve all of the sensory modalities, encompass numerous taxa of organisms, and occupy extremely varied ecological contexts. Mimicry is a multidimensional phenomenon, and it is hard to imagine it could be fully captured by some simple definition. Yet one notices that what the various instances of mimicry share is meaning, meaning that connects different organisms or entities through a web of resemblance and deception.

The juxtaposition of biological and semiotic approaches to mimicry can be fruitful also because of the rich conceptual tools which semiotics can contribute. Charles S. Peirce and his followers in their writings on semiotics speak of icons, a type of sign that is based on the similarity or resemblance between a sign and its object. Icons can be divided into subtypes based on their level of mediation and conventionality, and this is why they can serve as a powerful analytical device in a discussion about the diversity of biological mimicry. Semiotics has also proven its usefulness in analyses of the foundations or basis of resemblance (Sonesson 2010), truth conditions, types of references involved in mimicry (Coletta et al. 2009; El-Hani et al. 2010), and in the interpretations of the fuzzy resemblances present in abstract mimicry (Maran 2017) and in mimicry rings (Kleisner and Markoš 2005; Kleisner 2015). By focusing on the formal aspects of mimicry systems and the functions of the different participants (including human observers), semiotics can help biology to better understand nature's diverse forms of mimicry.

\section{Overview of Papers of the Special Issue}

This special issue includes ten research papers on the different aspects and perspectives on mimicry, from revisions to mimicry theory and its classical examples, all the way to building connections between biological mimicry and the different expressions of imitation in human behaviour and culture. What links all these papers is the attention they pay to communication and meaning production.

Enrique Font critically evaluates some recent conceptual frameworks for the study of mimicry in his essay 'Mimicry, Camouflage and Perceptual Exploitation: The Evolution of Deception in Nature'. He navigates the reader throughout the various cases of mimicry and discusses several border phenomena related to mimicry, such as background matching, masquerade, sensory traps, perceptual exploitation, and especially deception and perceptual error, ultimately providing the reader with an updated definition of mimicry. In his view, "Mimicry is the resemblance/similarity in appearance and/or behaviour between a mimic and a model that provides a selective advantage to the mimic because it affects the behaviour of a receiver, causing it to misidentify 
the mimic" and that it "evolved (or is maintained by selection) because of those effects."

Jindřich Brejcha, in his contribution 'Viper as a Batesian Model: Its Role in an Ecological Community' explores the idea that vipers may play the ecological role of Batesian models for imitators of various taxonomic origins, including reptiles, birds, and even invertebrates. This is possible thanks to the viper's zig-zag pattern, which signals danger to potential predators who avoid vipers as prey.

Victoria Alexander's contribution, 'The Mechanism for Mimicry: Instant Biosemiotic Selection or Gradual Darwinian Fine-Tuning Selection?' emphasises the saltational nature of mimicry evolution. In her view, biosemiotics offers an explanation of how new mimics can be instantly generated in nature by perceivers' misinterpretation of a physical object as a sign.

Richard I. Vane-Wright approaches mimicry from a 'process of life', rather than from a 'process of change' approach in his paper 'Agency, Meaning, Perception, and Mimicry: Perspectives from the Process of Life and Third Way of Evolution'. From a process of life perspective, he argues, it should be possible to define mimicry in a purely functional way that emphasises the immediate individual advantage mimics acquire when they, for instance, avoid being attacked by a predator. A functional definition of mimicry thus requires neither fitness nor natural selection (nor other such traditionally Darwinian criteria). In conclusion, Vane-Wright proposes a revision of his classical definition of mimicry from 1980 (Vane-Wright 1980). He now wishes to claim, instead, that "Mimicry is a functionally tripartite ecological relationship in which a living organism (the mimic), by simulation of signal properties (i.e. the properties used in the interpretation process of the receiver) of another living organism (the model) that have specific meaning for a third living organism (the receiver), becomes misinterpreted by the receiver, which, in accordance with its perception of the similarity, acts as if the mimic were an example (or instance) of the model, resulting in at least some momentary advantage to the mimic."

Karel Kleisner and S. Adil Saribay in their paper on 'The Dual Nature of Mimicry: Organismal Form and Beholder's Eye' argue that although natural selection does play some role in the evolution of mimicry, it does not satisfactorily explain either mimicry's origin nor its functioning. The same morphogenetic processes which built the bodies of model organisms are often responsible for the resemblance between the models and their mimics. It would seem therefore that mimicry is not just skin deep, they argue. Instead, in many cases, it is based on organisational processes shared by the mimic and the model. Regardless of its modality, they conclude, structural resemblance between two organisms produces opportunities that can be in certain ecological contexts exploited by meaning-attributive processes leading to functional mimicry.

Göran Sonesson explores the interface of visual semiotics, iconicity, and mimicry in his paper 'On Mimicry, Signs and Other Meaning-Making Acts. Further Studies in Iconicity'. He most helpfully links mimicry studies to the work of renowned authorities in semiotics: Charles S. Peirce, Terrence Deacon, and Luis Pietro. Sonesson emphasises what makes a sign what it is (i.e., that something is recognised as something) and in his nuanced criticism spells out the paradoxical nature of mimicry, namely that "animal mimicry, camouflage, and the like, in contrast, work as such only to the extent that they are not perceived as signs". 
The subject of mimicry is also relevant to understanding human cultural processes. John Pickering's paper 'Natural, Un-Natural, and Detached Mimicry' links biological mimicry, human behavioural and cognitive imitation (mimesis), and the falsity of extensive mediated communication (simulacra) of our time into a single framework and argues for continuity between these phenomena. Yogi Hendlin follows up on this line of thought in his paper 'I Am a Fake Loop: The Effects of Advertising-Based Artificial Selection', where he offers a critical examination of some mimicry-like processes in human economic activity and in advertising. He applies the classical ethological concept of supernormal stimuli to analyse marketing strategies and suggests that playful remodelling could act as an antidote against commercial mimicry.

Elis Aldana and Fernando Otálora-Luna in their contribution entitled 'Artistic Notion of Mimicry, a Case Study: Does Triatoma maculata (Hemiptera: Reduviidae: Triatominae) Plagiarize Bees, Tigers or Traffic Signals?' present a creative exploration of connections between mimicry, hermeneutic philosophy, and human evaluation of mimetic forms. The authors link the Chagas disease, common in Central and South America, and the mimicry of its vector, the insect Triatoma maculata, and argue that the lack of attention to the disease and this insect's reputation of a plagiariser are related.

Pauline Delahaye in her 'Ritual Mimicry: A Path to Conceptual Comprehension' discusses social imitation in primates, especially the Langur monkeys (Semnopithecus entellus), in proximity of their dead relatives. She argues that imitative behaviour in such 'death rituals' can help manage emotions and maintain social cohesion even in non-human animals. Both this contribution and Aldana's and Otálora-Luna's paper demonstrate the vast complexity of mimetic relations and the wide scope of possible interpretations.

In sum, it is our hope that this Special Issue manages to bring to light some of the more interesting current developments in mimicry studies, and to show that despite its long history, there are still fresh and exciting perspectives and new knowledge in the field to be found.

\section{References}

Bates, H. W. (1862). Contributions to an insect fauna of the Amazon valley. Lepidoptera: Heliconidæ. Transactions of the Linnean Society. Zoology, 23, 495-566.

Coletta, W. J., Wiegand, D., \& Haley, M. C. (2009). The semiosis of stone: A "rocky" rereading of Samuel Taylor Coleridge through Charles Sanders Peirce. Semiotica, 174, 69-143.

El-Hani, C. N., Queiroz, J., \& Stjernfelt, F. (2010). Firefly femmes fatales: A case study in the semiotics of deception. Biosemiotics, 3(1), 33-55.

Emsley, M. G. (1966). The mimetic significance of Erythrolamprus aesculapii ocellatus Peters from Tobago. Evolution, 20(4), 663-664.

Kleisner, K. (2015). Semantic organs: The concept and its theoretical ramifications. Biosemiotics, 8(3), 367379.

Kleisner, K., \& Markoš, A. (2005). Semetic rings: Towards the new concept of mimetic resemblances. Theory in Biosciences, 123(3), 209-222.

Komárek, S. (2003). Mimicry, aposematism and related phenomena. Mimetism in nature and the history of its study. München: Lincom Europa.

Maran, T. (2010). Semiotic modeling of mimicry with reference to brood parasitism. Sign Systems Studies, $38(1 / 4), 349-377$. 
Maran, T. (2017). Mimicry and meaning: Structure and semiotics of biological mimicry (Biosemiotics 16). Cham: Springer.

Mertens, R. (1956). Das Problem der Mimikry bei Korallenschlangen. Zoologische Jahrbücher (Systematik), $84,541-576$.

Müller, F. (1878). Ueber die Vortheile der Mimicry bei Schmetterlingen. Zoologischer Anzeiger, 1, 54-55.

Peckham, E. G., \& Peckham, G. W. (1892). Ant-like spiders of the family Attidae. Occasional Papers of Natural History Society of Wisconsin, 2, 1-84.

Quicke, D. L. J. (2017). Mimicry, crypsis, masquerade and other adaptive resemblances. Hoboken: Wiley. Sonesson, G. (2010). From mimicry to mime by way of mimesis: Reflections on a general theory of iconicity. Sign Systems Studies, 38(1/4), 18-66.

Vane-Wright, R. I. (1980). On the definition of mimicry. Biological Journal of the Linnean Society, 13(1), 1-6. Wickler, W. (1968). Mimicry in plants and animals. New York: McGraw-Hill.

Publisher's Note Springer Nature remains neutral with regard to jurisdictional claims in published maps and institutional affiliations. 